\title{
UMA MORTE DIGNA AOS SOFREDORES BRASILEIROS
}

\author{
Larissa Valbert ${ }^{1}$
}

RESUMO: Este artigo tem como objetivo analisar uma das mais famosas polêmicas da Bioética que é a eutanásia, onde pode-se observar muitas confusões envolvendo este tema no mundo inteiro. Será apresentado neste texto primeiramente a passagem histórica da eutanásia, mostrando que ela está presente desde a Antiguidade nas civilizações. Assim, explicaremos o que é a eutanásia, que tem como principal objetivo dar uma morte digna ao enfermo que sofre de dores agonizantes, dando o seu livre arbítrio e o direito de escolha na hora que deseja morrer. Esses são as perspectivas a favor da legalização da eutanásia, porém há muitas contrárias. A que irei apresentar é as das religiões que são quase todas contra o uso e a legalização deste método, principalmente aqui no Brasil; que desde que foi colonizado as religiões estão enraizadas no governo. Finalizaremos, mostrando que se deve sim aprovar a eutanásia no Brasil, pois ninguém sabe o que a outra pessoa está passando com a doença que tem, devendo assim, respeitar a individualidade de cada um e apresentaremos como pode-se criar as normas para utilizar da eutanásia no Brasil.

Palavras-chave: Eutanásia. Morte digna. Religião. Direito de morrer. Familiares.

ABSTRACT: This article aims to analyze one of the most famous controversies of Bioethics that is euthanasia, where it can be observed many confusions involving this theme worldwide. The historical passage of euthanasia will be presented in this text, showing that it has been present since antiquity in civilizations. Thus, we will explain what euthanasia is, whose main objective is to give a dignified death to the sick who suffers from agonizing pains, giving their free will and the right to choose at the time they wish to die. These are the prospects for the legalization of euthanasia, but there are many opposites. The one I will present is those of religions that are almost all against the use and legalization of this method, mainly here in Brazil; that since it was colonized religions are rooted in the government. We will conclude by showing that euthanasia should be approved in Brazil, because no one knows what the other person is going through with the disease they have, so they should respect the individuality of each and we will present how to create the norms to use euthanasia in Brazil.

Keywords: Euthanasia. Worthy death. Religion. Right to die. Relatives.

\footnotetext{
${ }^{I}$ Formação acadêmica: Graduação (graduando) em Direito. Instituição: Pontifícia Universidade Católica de Campinas
} 


\section{INTRODUÇÃO}

Cuando las condiciones de salud se han perdido y la enfermedad lleva a quien la padece a una situación irreversible, cabe preguntarse si se está cuidando la vida o prolongando la agonía. (BAREA, 2007) ${ }^{2}$

Um dos principais dilemas do mundo atual é como as pessoas enxergam a morte. $\mathrm{Na}$ maioria das vezes, a população vê a morte como um bicho de sete cabeças, que não pode ser falada e nem discutida em momento algum, onde somente se deve tentar fugir dela a qualquer custo, pois não se sabe com certeza absoluta para onde se vai após morrer, só existe hipóteses. Por este motivo, se criou tantos meios de prolongar a vida, como os transplantes, tratamentos de doenças e a criogenia.

Só sendo possível assim, a manutenção e prolongamento da vida pelo desenvolvimento da tecnologia, fazendo questionar-se até quanto é propício investir nisto e quando deve-se parar. Sendo estes também, os dilemas da eutanásia, distanásia, suicídio assistido e ao morrer com dignidade.

Como sabe-se, estes casos apresentados acima são do fenômeno da Bioética que tem como principal objetivo analisar novas invenções médicas que surgem ao longo dos séculos XX e XXI. Dizendo assim, se são ou não aceitáveis para utilizá-las no dia a dia de uma sociedade. Porém, aqui iremos tratar de apenas uma das várias discussões da bioética, que é o caso da eutanásia, onde sua criação ascendeu um acalorado debate entre cientistas, médicos, juristas e religiosos.

Eis aqui uma questão emblemática da contemporaneidade. Onde irá se examinar quais os principais dilemas que surgiram para a decisão. Analisando-se assim, se vai ser permitido ou não a utilização da eutanásia em um determinado país.

Ou seja, a eutanásia é um tipo de medicamento onde se utiliza para matar uma pessoa sem dor. Onde a principal causa do uso deste medicamento, é para enfermos que possuem doenças que tem como efeito dores terríveis e não há mais nada que possa fazer para saná-las, tendo como consequência a perda de sua dignidade humana. Mas, este uso só será permitido se o paciente fizer o pedido voluntário e explícito, se não se considerará um assassinato.

\footnotetext{
${ }^{2}$ Quando as condições de saúde se perdem e a doença leva o sofredor a uma situação irreversível, vale a pena questionar se ele está cuidando da própria vida ou prolongando a agonia.
} 
Como todas devem saber, a questão da aprovação nos países para o uso da eutanásia é bem polêmica. Sendo assim, um assunto de extrema atualidade, pois se é discutido em diversos países. Onde o Brasil se encontra em um estágio de amadurecimento de ideia sobre o assunto. Por conta, da eutanásia não ser somente um medicamento para ser utilizado em pessoas com doenças graves e terminais, mas também por gerar uma grande discussão em sua utilização em pessoas com uma depressão tão grande que não se possui cura.

Vale salientar, que o primeiro país a legalizar o uso da eutanásia foi a Holanda em abril de 2002. Sendo assim, uma grande vitória e uma vasta influência, para os outros países que estão analisando esta questão. Valendo-se ressaltar, que o parlamento de Portugal legalizou o uso da eutanásia no dia 29 de janeiro de 2021, mostrando-se como esta questão é atual no mundo jurídico.

Desta maneira, iremos expor sobre as questões que embargam a legalização da utilização da eutanásia no Brasil. Mostrando os principais motivos deste fato, não ser aprovado pelo Supremo Tribunal Federal.

As metodologias utilizadas neste artigo serão basicamente três. A primeira é a historiografia jurídica onde usarei como base a autora Maria Julia Kovàcs, que apresenta maravilhosamente, um breve histórico de como já existia a eutanásia na Antiguidade, expondo vários exemplos de civilizações que faziam isto, só que de uma maneira um pouco diferente da atualidade e também expõe as perspectivas dos religiosos com relação a legalização da eutanásia. A segunda é a análise morfológico dos diferentes significados das definições da utilização da eutanásia que foi usado como base os autores Rodrigo Siqueira Batista e o Fermin Roland Schramm. Por fim, a terceira é a utilização dogmática sobre tipos de argumentos a favor sobre a legalização da eutanásia, feita com base na autora Cecília Regina Alves Lopes.

\section{PASSAGEM HISTÓRICA}

O termo eutanásia tem origem na Grécia, tendo como significado boa morte ou morte digna. Foi usado pela primeira vez pelo historiador Suetônio, no século II d.C., ao resolver descrever a morte "suave" do imperador Augusto: "A morte que o destino lhe 
concedeu foi suave, tal qual sempre desejara: pois todas as vezes que ouvia dizer que alguém morrera rápido e sem dor, desejava para si e para os seus igual eutanásia (conforme a palavra que costumava empregar)” (Suetônio, 2002). Séculos depois, foi utilizado este termo por Francis Bacon, em 1623, onde em sua História vitae et mortis usou a palavra eutanásia, sendo como o “tratamento adequado às doenças incuráveis” (apud Jiménez de Asúa, 1942).

Horta (1999) apresenta uma linha histórica sobre a eutanásia, expondo que na sociedade greco-romana, já se existia o direito de morrer e permitia-se também aos doentes desesperados, que pudessem por fim a uma vida de sofrimento; esses direitos foram interrompidos quando a vida foi considerada um dom de Deus. Já em I605, volta-se este assunto com Francis Bacon, onde ele apontava que este tema era de assunto médico, tendo como objetivo aliviar a dor de pacientes terminais; desta maneira, quando fosse necessário poderiam apressar-lhes a morte.

Porém, na França (1999) discutia-se o direito de matar e de morrer. Na Grécia, os famosos espartanos, jogavam seus recém-nascidos defeituosos e seus idosos do alto de um monte. Em Atenas, o Senado que decidia sobre a eliminação dos idosos e dos enfermos incuráveis. Em Roma, César dava autorização para se sacrificar seus gladiadores feridos, para assim cessar suas dores. $\mathrm{Na}$ Índia, as pessoas com doenças incuráveis eram jogadas no Ganges. Na Idade Média, os guerreiros feridos mortalmente, tinham o direito de serem mortos por punhais, para não se prolongar seu sofrimento.

Assim, podemos perceber que na Antiguidade, o uso da eutanásia já era permitido para a eliminação das crianças imperfeitas e como forma de sanar o sofrimento da pessoa. $\mathrm{Na}$ atualidade, percebe-se que se têm quase o mesmo intuito com a eutanásia, que é o de aliviar a dor dos sofredores, que não se tem mais solução. Porém, se possui uma grande polêmica, por conta dos preceitos religiosos dos políticos e da população que se misturam para sua aprovação nos países.

\section{O QUE É A EUTANÁSIA?}

Podemos assim dizer que, a essência da eutanásia se dá quando uma pessoa possuiu uma doença incurável ou está em um estado terminal de vida e tem o desejo de por fim, a aquela dor irremediável. Este "tratamento" tem como objetivo provocar conscientemente a 
morte de alguém, fundamentado pelo valor da moral, por motivo de piedade ou compaixão e para acabar com a angústia dela. Ou quando o paciente com livre arbítrio escolhe este método. Desta maneira, ao invés de aguardamos a morte ocorrer, busca-se amenizar o sofrimento do paciente, com a utilização da eutanásia, para antecipar esta morte e acabar com sua consternação.

Desta forma, dois pensadores pensaram em formas distintas de qualificar a eutanásia, onde classificam o ato em si (Neukamp, 1937):

a) Eutanásia ativa: ato voluntário de causar a morte sem sofrimento do enfermo

b) Ortotanásia (que era chamada de eutanásia passiva): quando ocorre a morte por omissão do médico, pois se tinha como objetivo de o tratamento garantir a continuidade da sobrevida

c) Eutanásia de duplo efeito: a morte é acelerada por meio de ações médicas, visando o alívio do sofrimento do paciente

Uma outra maneira de se classificarem as várias modalidades de eutanásia, leva em conta não só a consequência, mas também o consentimento do paciente (Martin, 1998):

I) Eutanásia voluntária: o paciente deliberadamente pede para morrer, o que pode ser considerado um suicídio assistido

2) Eutanásia involuntária: um ato que leva a morte do enfermo, sem sua autorização

3) Eutanásia não voluntária: quando a morte é levada a cabo, sem se conhecer à vontade rela do paciente

Esses autores têm como principal foco a questão da liberdade de escolha do paciente, onde deve-se ter a liberdade de escolher viver ou morrer, sendo assim a antecipação voluntária da morte. Mas, somente deve-se ter esta opção de escolha quando tiverem uma doença que cause muita dor ou que tire sua dignidade humana e que a permissão do enfermo para a utilização do método fique bem clara.

\section{PONTOS DE VISTA RELIGIOSO SOBRE A EUTANÁSIA}

As religiões no Brasil estão impregnadas nos seus governos desde seu surgimento. Quando os portugueses descobrirem o Brasil e foram colonizá-lo, a primeira coisa que quiseram fazer foi catequisar os indígenas. Desta forma, podemos perceber que a religião desde a criação do Estado, sempre esteve atrelada a tudo que ele fazia. 
Mas, a religião tem seu papel importante em apresentar maneiras de para onde iremos após a morte, assim confortando milhões de pessoas. As vezes, ajudando as pessoas que estão sofrendo, oferecendo reflexões e acolhimento. De toda forma sempre estará interligada com o sentido da vida, justiça e direcionamento da consciência. Sendo assim, muito importante para toda a humanidade.

Buscam também, uma ética de responsabilidade, discutindo as consequências de certas ações do governo. E assim cabe-se elas a discussão sobre a eutanásia, onde se influência muito estas certas decisões no país, dependendo da opinião das suas religiões que ali são majoritárias. Aqui iremos apresentar opiniões contrárias sobre a legalização da eutanásia.

\subsection{Cristianismo (123 milhões BR)}

No Cristianismo, o uso da eutanásia é condenado como violação da lei de Deus, ofensa à dignidade humana e um crime contra a própria vida. Porém, isto não quer dizer que se deve prolongá-la a todo o custo, aumentando o tempo que a pessoa irá sofrer.

Aqui aceita-se que a pessoa tenha a possibilidade de parar de fazer certos tipos de tratamentos para se curarem de suas doenças que são incuráveis, onde causam muita agonia e sofrimento. Deixando assim, a pessoa morrer naturalmente, o que não quer dizer permitir que a mate por isso.

\subsection{Espiritismo ( 3,8 milhões)}

No espiritismo toda a maneira que abrevia a vida no corpo físico é contraditória aos Códigos Divinos. Desta maneira, sabe-se que a vida pertence a Deus e somente ele tem permissão para retirá-la.

Muitas pessoas dizem que o médico tem o dever de aliviar a dor do enfermo, quando não se tem cura sua doença, proporcionando assim para ele uma morte calma e indolor. Porém, para os espiritas só compete a Deus promover o retorno à Espiritualidade; pensa-se também que ninguém pode afirmar com absoluta certeza que o enfermo não tem chance nenhuma de melhora e que esta condenado a sofrer (exemplo: a literatura médica apresenta muitos casos onde milagrosamente pessoas que estavam condenadas a morrer se recuperam); acredita-se que se utilizar a eutanásia se interromperá a depuração do Espírito, 
uma vez que antecipada sua partida, provocando assim sua desencarnação, se ocorrer isto o desencarnado terá sérias dificuldade de retornar ao Plano Espiritual.

Os familiares muitas vezes tomam decisões precipitadas, pois não aguentam ver o seu parente sofrendo tanto, por conta de se encontrar num estado irreversível. Pensando assim, que a melhor solução é acabar com suas dores e agonias, interrompendo sua vida na Terra. Há inclusive os familiares que no fundo de sua alma desejam se livrar do trabalho de ter que ir aos hospitais todos os dias e visitar seu ente querido.

Um exemplo de um caso em que não se utilizou eutanásia em si, mas causou esta partida surpresa serias dificuldades no plano espiritual:

André Luiz, no seu livro “Obreiros da Vida Eterna”, relata a eutanásia a que foi submetido um trabalhador da seara espírita chamado Cavalcante. O médico, aproveitando a inconsciência do moribundo e sem autorização dos familiares, aplicou-lhe uma dose letal de anestésico.

O períspirito de Cavalcante também é alcançado pelo medicamento e CavalcanteEspírito vê-se atordoado, incapaz de qualquer atitude.

Em face do ocorrido, o desprendimento do desencarnante só pôde ocorrer após 20 horas do previsto pelos espíritos amigos.

Ainda assim, Cavalcante não se retirou em condições favoráveis e animadoras. Apático, sonolento, desmemoriado, foi recolhido num departamento espiritual, demonstrando necessitar de maiores cuidados. (ROSSIT, 2019)

Aplica a eutanásia em culturas muito antigas para se ter uma morte feliz, porém esta tomada de decisão deixa o paciente infeliz, além de se considerar um lamentável desrespeito aos desígnios de Deus.

\subsection{Budismo (243 mil)}

No Budismo, não se possui uma autoridade suprema, sendo o objetivo de todos os budistas a iluminação, desta forma cada pessoa tem como missão traçar seu próprio caminho como o próprio Buda. Uma filosofia de vida é ter cada um tem seu caminho de sabedoria. A vida sempre será transitória e a morte inevitável, sendo importante que cada um siga o seu transcurso natural. Além disso, a morte perturba o processo dos sobreviventes e não deve ser prolongada quando não houver possibilidade de recuperação, mas não deve a morte ser adiantada. Sendo assim, o momento da morte fundamental, pois o que governa o renascimento é a consciência da aprendizagem da hora de morrer. 
O transplante não é aceito nesta religião, pois o corpo e o espírito são uma unidade que continuam após a morte. Quando se remove um órgão do corpo de uma pessoa morta esta unidade é perturbada. O suicido não é aceito, pois é visto como um escape de passar pela transição de morrer na hora correta.

As drogas para sanar a dor do enfermo são aceitas, mesmo que possam matá-lo. Entretanto, é importante analisar se necessário mesmo a utilização delas, pois é importante na hora da morte o paciente ter o máximo de lucidez possível. No budismo, valoriza-se muito a possibilidade de se ter uma decisão pessoal sobre o tempo e a forma da morte. Assim, a vida é do homem e não divina, e a preocupação é com a evolução da pessoa.

\subsection{Judaísmo (103 mil)}

A grande base do judaísmo é decidir quando será o momento da morte da pessoa. Sobre a eutanásia, na opinião dos rabinos a morte não deve ser apressada e o enfermo deve receber os tratamentos dos quais necessita. A decisão da própria morte não cabe ao sujeito, e sim aos rabinos que ao interpretar a Torah, aplicam seus conhecimentos obtidos nela em seu dia a dia. Mesmo não tendo cura a doença, não se deve deixar de cuidar do enfermo, e ele não deve ser deixado sozinho na hora de sua morte. Sendo o médico o servo de Deus, não devendo apressar a morte de seu paciente. Devendo sempre ser preservado a vida, e não a agonia.

\subsection{Islamismo (35 mil)}

Islamismo significa ser submisso a Deus. Sendo a vida sagrada, devendo ser feito de tudo para protegê-la; o mesmo vale para o corpo que não deve ser mutilado em vida e nem após a morte.

Deus é a suprema força que governa os homens, assim, o suicídio é considerado uma transgressão. O médico sendo um mero instrumento de Deus para salvar a população, não podendo tirar a vida de ninguém, nem mesmo por piedade; mas não devendo prolongá-la a todo custo, principalmente quando a morte já é certa. 


\section{POR QUE A EUTANÁSIA NO BRASIL NÃO É APROVADA?}

Como bem se sabe, esta temática é muito recente dado que começou sua discussão somente no século XX. Por este motivo muitas legislações não a incorporarão, pelo fato de trazerem muitas controvérsias. As principais polêmicas podem ser observadas quando se possibilita uma morte digna e também numa outra perspectiva como se outra pessoa que autoriza este procedimento, está cometendo um homicídio da pessoa enferma.

Esta autorização para se utilizar a eutanásia no Brasil é bem complicada, pois mexe com discussões de ordem ética, religiosa, social e cultural. Por causa de se ter diversas opiniões sobre este assunto, dificultando assim muito, uma decisão que todos saiam satisfeitos.

Por isso, iremos observar os argumentos de se conceder a legalização da eutanásia:

I. Direito de uma morte com dignidade: A maioria das doenças se desenvolvem lentamente no corpo, sem nem percebermos. Como sabe-se o tratamento da enfermidade é bem demorado, e é sempre associado a dor e sofrimento. Este é o pensamento das pessoas que tem o desejo de morrer com dignidade. A morte que se deseja é a mote rápida, sem dor, de preferência quando se estiver dormindo, onde nem se percebe que morreu. A morte sem dignidade, é aquela temida por todas as pessoas, ou seja, aquela lenta, dolorosa e onde o enfermo vai definhando pouco a pouco. Desta forma, sabemos que temos direito a dignidade humana, que está previsto no art. $\mathrm{I}^{\circ}$, inciso III na $\mathrm{CF}$, onde não pode nos ser negado e então porque não se pode ter o direito garantido de morrer com dignidade.

Portanto, o objetivo de se querer e ter a possibilidade de a legalizar a eutanásia é pela possibilidade de o enfermo ter pelo menos uma morte digna, pois já perdeu a sua dignidade humana. É também uma qualidade inerente ao ser humano, que protege contra todo o tratamento degradante sofrido, o assegurando condições mínimas de sobrevivência. Por ser um princípio fundamental a dignidade, o Estado deve protegê-la.

2. Direto de morrer: este fundamento está assegurado no direito pela liberdade de escolha, no exercício do livre arbítrio, quando pode escolher viver ou morrer. Como sabe-se escolhemos tudo em nossa vida e dificilmente somos questionados por isto, mas quando se trata de escolher se deseja viver e morrer, as vozes contrárias são muitas e o apoio a este 
direito fundamental não é assegurado pela lei. Afinal de contas, quem detêm o direito a vida e a morte sobre nós mesmos? Perguntamo-nos.

3. Direito de fazer aquilo que desejar com o próprio corpo: $O$ direito sobre a própria vida está ligado ao direito à vida privada, à intimidade, à honra, à imagem, etc. Sendo assim, o direito à vida inerente a cada ser humano, o que fazer desta vida é de responsabilidade de seu detentor. Assim, podemos perceber que as pessoas possuem dois momentos, o primeiro da vida social e o segundo para si mesmo, onde não diz respeito a ninguém e nem o Estado deve intervir.

4. Custos sociais: Justifica-se os pró-eutanásia, que os gastos com pacientes em estado terminal sobrecarregam demais as instituições (públicas e privadas), bem como suas famílias. Sendo, o quadro clínico do enfermo irreversível, para eles seriam mais econômicos acabar com suas despesas.

5. Sofrimento dos familiares: É muito desgastante para os familiares terem que assistir o ente querido morrendo aos poucos, principalmente quando as doenças duram anos a fio. Desta forma, o sofrimento destes parentes só teria fim com a morte destes.

Um exemplo da utilização da eutanásia é de uma americana que teve o diagnóstico de seu agressivo tumor cerebral. Onde descobriu que não tinha cura e que teria apenas mais 6 meses de vida, assim ela resolveu utilizar a droga para morrer com dignidade. Pois, ela iria apenas piorar e ficar sofrendo aguardando seu terrível fim, então foi possível ela ter sua morte digna e sem sofrimento.

Outro exemplo é a do filme "Como eu era antes de você" que apresenta fatos verídicos. Onde um jovem que vivia a vida intensamente é atropelado por uma moto, ficando assim quadriplégico, sem poder fazer nada mais e tendo que viver dependendo dos outros. Podendo analisar assim, que ele perdeu sua dignidade humana e consequentemente sofreria muito se continuasse vivo. Pois todo momento precisava fazer fisioterapia e possuindo também uma saúde muito frágil. Podendo assim, prever que não viveria por muito mais tempo. Desta forma, ele decidiu fazer o suicídio assistido para acabar com a tortura de viver, sem poder se movimentar novamente e com o sofrimento de relembrar o que viveu, não podendo fazer mais isto. 
Assim, como os dois últimos casos, a medalhista paraolímpica Marieke Vervoort que optou pela utilização da eutanásia. A campeã tinha uma doença muscular generativa incurável que lhe causava dores constantes, paralisia nas pernas e não a deixava dormir. Fazendo assim, com que ela se opta pela eutanásia, para finalmente cessar seu sofrimento constante com as dores no corpo.

Esses casos fazem nos perguntar se existe um direito fundamental a não sentir dor, se analisarmos, ele já está inserido no direito a saúde de certa forma. Visto que surgiram muitos remédios que previnem a dor em si, como anestesias para fazerem procedimentos cirúrgicos, para que a pessoa não sinta nada. Em outras palavras o principal objetivo do remédio não foi para curar, mas para ajudar com que a dor que estavam sentindo passasse e assim curando aquela doença no processo.

Pode-se perceber que todo tipo de doença esta relacionado a sentir algum desconforto corporal, então podemos perceber que o mau do século é a própria dor e como podemos torná-la suportável ou inexistente. Uma das soluções encontradas para isto foi a eutanásia que acabava com a dor e o sofrimento do enfermo, pois nenhum outro remédio foi descoberto para amenizar de modo aceitável a dor daquela pessoa.

Este conceito também coloca em questão a dor física e a dor psicológica, o que causa uma polêmica em países, que já autorizam o uso da eutanásia. Um dos principais motivos é o fato de que muitas pessoas que estão com depressão desejaram se matar. Com o consentimento da eutanásia no Brasil, muitas irão querer utilizá-la. Será que esta dor poderá ser aceita?

É bem difícil enxergar o Brasil aceitando facilmente a utilização da eutanásia para casos de doenças com dores constantes, por conta da existência de muito grupos religiosos que não aceitariam isto. Já que a grande maioria da população brasileira é católica ou evangélica e possuem grande poder no governo, apesar de estar escrito na Constituição Federal que se é um Estado laico. Outra adversidade encontrada é com o Código Penal no art. $122^{\circ}$ que qualifica o suicídio como crime, imagina permitir uma pessoa se matar por não aguentar as dores, será visto como um suicídio assistido. Se observarmos a utilização da eutanásia para uma pessoa com depressão será visto também como uma forma de suicídio. 
O que primeiramente precisa-se fazer é mudar as normas jurídicas brasileiras para ser possível a utilização, em pelo menos a utilização para a dor física. Pelo motivo de sabermos que irá demorar mais meio século para as pessoas do governo amadurecerem seus pensamentos e aprovarem o uso da eutanásia com sofrimentos psicológicos das pessoas.

Por fim, ainda há muito a ser entendido sobre o sofrimento físico e psicológico que leva uma pessoa a desejar a utilização da eutanásia. Mas deve-se permitir pelo menos que o enfermo tenha a possibilidade de ter o poder de escolher se deseja ou não viver com aquela dor que para ele é interminável.

\section{COMO DEVE-SE DAR A REGULAMENTAÇÃO DA EUTANÁSIA NO BRASIL, SE FOR APROVADA}

Após analisarmos a fundo os pros e contras da legalização da eutanásia, podemos observar que uma das principais preocupações com esta aprovação é se este medicamento será utilizado de maneira indevida. Como por exemplo, podendo ser utilizado para matar os enfermos nas redes públicas, onde os mais pobres utilizam, estando em uma situação em que apenas aguarda-se que se desligue seus aparelhos (só ocupando espaço no hospital, onde se falta vagas muitas vezes) ou em todos os tipos de hospitais onde familiares mandam matar seus familiares que dão muito trabalho e gastos a eles, que estão muitos doentes.

Por isso, irei apresentar normas que irão garantir o uso seguro da eutanásia, para ser possível utilizá-las no Brasil. São elas:

I. A eutanásia deve ficar num local específico, separado dos hospitais, ou seja, no laboratório que se irá ser produzida.

2. Para se obter este medicamento o médico precisa fazer um requerimento com provas concretas de que a pessoa está com uma doença, que se enquadra no uso da eutanásia e se o enfermo esta consciente e tem absoluta certeza de sua decisão.

3. Após a certificação da real necessidade de sua utilização, irá até o hospital um médico designado do Governo (que só analisa o uso do medicamento) que é responsável por levar ao hospital a eutanásia e ele mesmo irá aplicá-la no enfermo. Mas, antes disto irá o médico conversar com o paciente para se certificar de sua decisão e depois disto poderá aplicar o medicamento.

4. Exceção: se o enfermo não estiver consciente, precisa-se ter um papel assinado pelo enfermo dizendo que deseja utilizar a eutanásia, sendo direta e explícita. Deverá ser comprovado que foi a pessoa que esta doente mesmo que 


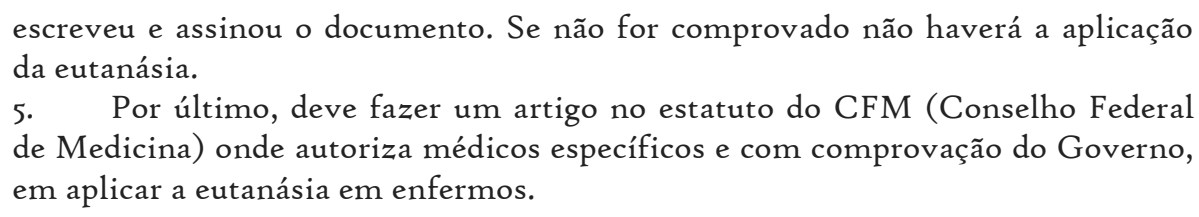

Todas essas medidas têm como objetivo que não se aplique o medicamento, por qualquer médico da rede privada ou pública, com intenção maliciosa, com o intuito de matar a pessoa por fato fútil. Também para que não haja venda do medicamento para outras pessoas, que desejam matar pessoas que não estão doentes e sim porque não gostam delas e desejam vê-las mortas.

\section{CONCLUSÃO}

Um primeiro ponto apresentado, é que desde a Antiguidade já havia o preceito da eutanásia, mas era de uma maneira diferente de como é na atualidade. Pois antigamente as pessoas eram mortas com facas, jogadas de montes e na contemporaneidade, elas iriam apenas tomar um remédio e morreram. Porém, o preceito era o mesmo, ou seja, o de acabar com a dor, sofrimento e agonia das pessoas.

O segundo ponto, apresenta diversas definições da eutanásia para compreender-se claramente como as pessoas enxergam de maneiras diferentes a utilização dela. Com estas qualificações pode-se concluir, que a maioria das pessoas só utiliza este método, pois nenhum outro funcionou para amenizar sua dor e a pessoa não aguenta mais sofrer, causando assim sua perda de dignidade humana.

No terceiro ponto, mostra-se como a religião é forte no Brasil. Geradora assim, de muitos conflitos em determinados assuntos, pois são elas que ajudam as pessoas a interpretarem o mundo e para onde iremos quando morrer. Assim, se apresenta-se as perspectivas de cinco religiões, sobre suas opiniões da legalização da eutanásia e consequentemente, todas são contra este método, por causa que a maioria diz que a vida é um presente de Deus e só ele pode decidir quando a tirar de nós.

No quarto, apresenta-se argumentos que apoiam a legalização da eutanásia que são: o direito de possuirmos o direito de morrer igual existe no direito a vida, o direito de ter uma morte digna, o livre arbítrio de fazer aquilo que deseja com seu corpo e o sofrimento de seus familiares. Para assim, mostrar porque deve haver a legalização na eutanásia no 
Brasil, mas com algumas regras para se administra este medicamento, ou seja, a pessoa tem que ter absoluta certeza e estar sã e tem que estar com uma doença terminal ou pode ter uma doença que cause uma dor insuportável. Porém, não será aceito por enquanto o uso da eutanásia em pessoas com depressão grave, pois estamos iniciando e entendo aos poucos o que deve ou não poder ser usado em determinadas situações.

No último ponto, apresenta-se normas que devem ser implementadas para o uso seguro da eutanásia, quando futuramente for legalizado o uso dela. Para evitar que haja a revende do medicamento a pessoas que não são autorizadas a usá-la e que médicos não usem de maneira errada a eutanásia.

Por fim, pode-se concluir que o principal objetivo de querer esta legalização da eutanásia é para respeitar a individualidade de cada pessoa, pois nós não sabemos o grau da dor do enfermo e o que ele passa com esta doença. Portanto, não se deve os religiosos se intrometerem em um assunto tão pessoal e nem os médicos, pois a dor é do paciente e ninguém tem o direito de dizer que a dor dele não é forte o bastante para ele não ter permissão de usar a eutanásia.

\section{REFERÊNCIAS BIBLIOGRÁFICAS}

ADONI, André Luis. Bioética e o Biodireito: aspectos gerais sobre a eutanásia e o direito à morte digna.

Disponível

em:

https://www.revistadostribunais.com.br/maf/app/resultList/document?\&src=rl\&srguid= ioad82d9aooooor 7822 b95 f 294 e2I5b8f\&docguid=Ioedd6f $70 f_{2511}$ dfab6foroooooooooo\&hitguid= Ioedd6 7 of $251 \mathrm{IIdfab6}$ foroooooooooo \& spos $=\mathrm{I} \&$ epos $=\mathrm{I} \& \mathrm{td}=39 \&$ context $=7 \& \mathrm{crumb}-$ action=append $\&$ crumb-

label=Documento\& is DocFG=true\& isFromMultiSumm=true\&startChunk= $=$ \&endChunk $=$ I Acesso em: 20 .mar. 202I

CUNHA, Ana Luisa Marzola da. Eutanásia e o direito brasileiro: uma análise sobre seus aspectos favoráveis e desfavoráveis. 2018. 
DONIZETTI, Elpidio. Princípio da dignidade da pessoa humana. Disponível em: https://elpidiodonizetti.jusbrasil.com.br/artigos/I21940203/principio-da-dignidade-dapessoa-humana-art-6-do-projeto-do-novo-cpc Acesso em: 13 .mar. 2021

FURST, Henderson. Sobre sonhar acordado, um jeito de não sentir dor. Disponível em: http://genjuridico.com.br/2019/II/I2/sonhar-acordado-jeito-nao-sentir-dor/ Acesso em: 20 .mar. 202I

FRANCISCO, Susete. Eutanásia. Número de pedidos aumenta todos os anos.

Disponível em: https://www.dn.pt/portugal/eutanasia-numero-de-pedidos-aumentatodos-os-anos-8959542.html Acesso em: 20 .mar. 2021

Gi. Ao menos 5 países permitem suicídio assistido ou eutanásia. Disponível em: http://gi.globo.com/ciencia-e-saude/noticia/2014/II/ao-menos-5-paises-permitemsuicidio-assistido-ou-eutanasia-veja-quais-sao.html Acesso em: 20 .mar. 202I

KOVÁSC, Maria Julia. Bioética nas questões da vida e morte. Revista de Psicologia da USP, 2003.

LOPES, Cecília Regina Alves. Eutanásia: a última viagem. RFD-Revista da Faculdade de Direito da UERJ, n. 19, 2011.

MAGALHÃES, Brenna Maria Carneiro Costa. Eutanásia: origem, ramificações e outras peculiaridades. Disponível em: https://ambitojuridico.com.br/cadernos/direitopenal/eutanasia-origem-ramificacoes-e-outras-peculiaridades/ Acesso em: 13 .mar. 202I

PRESSLY, Linda. Eutanásia: a jovem com problemas psiquiátricos que conseguiu ajuda dos médicos para morrer. Disponível em: https://www.bbc.com/portuguese/geral45144669 Acesso em: 3.abril.2021 
PORFÍRIO, Francisco. Bioética. Disponível em: https://mundoeducacao.uol.com.br/filosofia/bioetica.htm Acesso em: 3.abril.202I

ROSSIT, Fernando. Eutanásia na visão espírita. Disponível em: https://www.kardecriopreto.com.br/eutanasia-na-visao-espirita/ Acesso em: I2.abril.202I

SIQUEIRA-BATISTA, Rodrigo; SCHRAMM, Fermin Roland. Eutanásia: pelas veredas da morte e da autonomia. Ciência \& Saúde Coletiva, v. 9, p. 31-4I, 2004.

SARLET, Ingo Wolfgang. A dignidade da pessoa humana. Revista de Direito Administrativo, v. 212, p. 84-94, 1998.

WELLE, Deutsche. Parlamento de Portugal aprova legalização de eutanásia. Disponível em: https://epoca.globo.com/mundo/parlamento-de-portugal-aprova-legalizacao-daeutanasia-24861113 Acesso em: 10.abril.2021 